\title{
Erratum to: Evaluating Effectiveness of Two Types of Chinese Remedial Materials for Low-Achieving and Disadvantaged Second Graders
}

\author{
Shu-Li Chen $\cdot$ Shih-Jay Tzeng $\cdot$ Szu-Yin Chu
}

Published online: 6 April 2014

(C) De La Salle University 2014

Erratum to: Asia-Pacific Edu Res

DOI 10.1007/s40299-013-0164-z

Unfortunately, one of the co-author's name was published incorrectly as Tzeng Shih-Jay. The correct name is ShihJay Tzeng.

The online version of the original article can be found under doi: 10.1007/s40299-013-0164-z.

\section{S.-L. Chen}

Department of Education Industry and Digital Media, National Taitung University, 369, Sec. 2, Shikang Rd., Taitung, Taiwan

\section{S.-J. Tzeng}

Department of Special Education, National Taitung University,

369, Sec. 2, Shikang Rd., Taitung, Taiwan

S.-Y. Chu $(\square)$

Department of Early Childhood Education, National Taitung

University, 369, Sec. 2, Shikang Rd., Taitung, Taiwan

e-mail: sychu@nttu.edu.tw 